\title{
Routes to Knowledge
}

\author{
Sue Howley
}

\section{Author}

Sue Howley is Senior Policy Adviser at the Museums, Libraries and Archives Council (MLA). Prior to this, she was Deputy Chief Executive and Head of Research in the Library and Information Commission.

Email: sue.howley@mla.gov.uk

\begin{abstract}
The Wider Information and Library Issues Project (WILIP) has now reported and is being followed-up. Many of the recommended actions will be implemented via the next, strategic stage -"Routes to Knowledge"- which seeks to re-position libraries in the Knowledge Society and develop capacity so their potential can be realised. Routes to Knowledge will engage with the library and information world to produce an Action Plan by March 2005. Actions will fall under headings such as user need, strategic framework, advocacy, network development, access, funding, workforce, information literacy and knowledge management. The relevance of these activities to research (and vice-versa) is discussed.
\end{abstract}

\section{Introduction}

In a previous issue of Library and Information Research (Howley and Ede, 2003), the authors described progress on what was then an on-going project - the Wider Information and Library Issues Project (WILIP). The primary aim of this project was to establish how the contribution made by library and information services to the economic, social, educational and cultural life of the UK can be maximised. A subsidiary aim was to identify what needed to be done to achieve this and by whom, and, in particular, to determine the ways in which the Museums, Libraries and Archives Council (MLA) - then called Resource - could best work with others to catalyse and promote the development of library and information services. MLA was established in April 2000 to work with and for museums, libraries and archives, providing strategic leadership, promoting innovation, developing capacity and acting as an advocate. It is a "non-departmental body", funded by grant-in-aid from the Department for Culture, Media and Sport, but with a wider remit than its sponsoring department. WILIP was led by a strategic partnership of the British Library (BL), the Chartered Institute of Library and Information Professionals (CILIP) and MLA.

The earlier article presented interim findings (but WILIP had already identified a vision for library services and the major issues that needed addressing to realise the vision) and drew out the research implications of those findings. The present article confirms the final conclusions of WILIP and describes the reporting arrangements and follow-up action. It then describes the next stage - "Routes to Knowledge" - which will respond to WILIP by establishing how all types of library and information service can be brought together to achieve their collective potential, raise their profile with decision makers and deliver increased benefits. Again, the research implications of these plans will be identified.

\section{The Wider Information and Library Issues Project}

\section{Background}

The main activity of the Wider Information and Library Issues Project was extensive consultation with all kinds of library and information service. Thirteen types of library/information service were identified for the purposes of the exercise. These were: school libraries, further education libraries, higher education 
libraries, public libraries, prison libraries, national libraries, corporate library and information services, government libraries, health libraries, research institution libraries, voluntary sector libraries, cultural and heritage libraries and "content providers". The last category was taken to include: print publishers, digital and other media publishers, distributors and other intermediaries (booksellers, wholesalers, library book suppliers, subscription agents, aggregators, etc) and other information providers, such as tourist information centres. A wide range of these interests was represented on a Steering Group, which was assembled to provide expert advice and guidance on the conduct and coverage of the consultation exercise and to help analyse the findings. A total of 77 organisations and over 200 individuals were involved in the consultation, which attempted to clarify the profession's vision for the future and the challenges that would need to be met in order to realise the vision.

\section{Findings}

A definite consensus emerged. Respondents identified four main elements for a shared vision for library and information services:

- Users will be information-literate and have seamless and unfettered access to information resources at the time and place of their choosing and in the form that they want, no matter where the resources are located.

- Access will be facilitated by more and more information being available electronically, including a wider range of older resources made accessible through digitisation.

- The library and information service will become increasingly the focus for access to the wider range of services.

- The library role will become more closely geared to customers' needs, supporting self-navigation by users, helping them develop information literacy skills or providing intermediation, according to their requirements.

Through the consultation, WILIP revealed four main issues which needed to be addressed in order to achieve this high level vision:

- Strategic framework. A framework that linked strategies for all types of library and information services was preferred to the idea of a single, monolithic "national information policy". The strategic framework should drive high level advocacy and capacity building work, focusing on policy areas such as: culture, health, education, economy, modernising and social policy.

- Advocacy. This focused on raising the profile of libraries and information services with government and other stakeholders through making clear their contribution and value in relation to major strategic priorities.

- Workforce and leadership development. There is urgent need to address issues of low esteem, skills gaps and leadership development through advocacy and through better co-ordination.

- Funding. The focus was not just on obtaining more funding but also on making better use of existing resources and demonstrating the value (particularly the economic value) of libraries and specific initiatives. Sustainability of initiatives was a particular issue.

As the Project Team and the Steering Group looked more closely at the findings, additional conclusions became clear:

- There is a huge potential in libraries collectively, which is not being realised - yet. 
- This is partly caused by continuing fragmentation in the sector, duplication of effort and resources, lack of strategic leadership, and therefore lack of influence in the higher reaches of policy and political power.

- To move forward, a coherent vision is needed of what libraries and other information services should now offer, and an initiative to rally library and information services to deliver that vision.

\section{The reports}

The Full Report (Ede, 2003), published in November 2003, detailed the consultation findings and issues raised. It also contained separate chapters on issues as they affected each of the 13 types of library and information service plus chapters on the regional perspective and on the perspectives of professionals in Wales and Northern Ireland. This was accompanied by a short summary report (Howley and Stevens, 2003) which described the process for handling the recommendations made during the consultation. There were 200 specific actions requested by respondents. Inevitably, the 200 actions ranged from the grand and glorious ("Get government departments working together and make sure they know the importance of libraries") to the very specific ("Standardise licensing terms"). But each one has been considered, in consultations involving, amongst others, the BL, CILIP and MLA. Many of them will be addressed through existing BL, CILIP or MLA programmes. More wide reaching recommendations will be taken forward in the next stage of the WILIP project: Routes to Knowledge.

\section{Routes to Knowledge}

\section{Programme plan}

The first stage of Routes to Knowledge will run between April 2004 and March 2005. A brochure will be circulated in April giving details. Routes will respond to the findings of WILIP, principally through a strategic advocacy programme and identifying ways in which the challenges identified in WILIP can be addressed to improve the capacity of libraries to realise their high level vision.

The programme for Routes is illustrated in Figure 1.

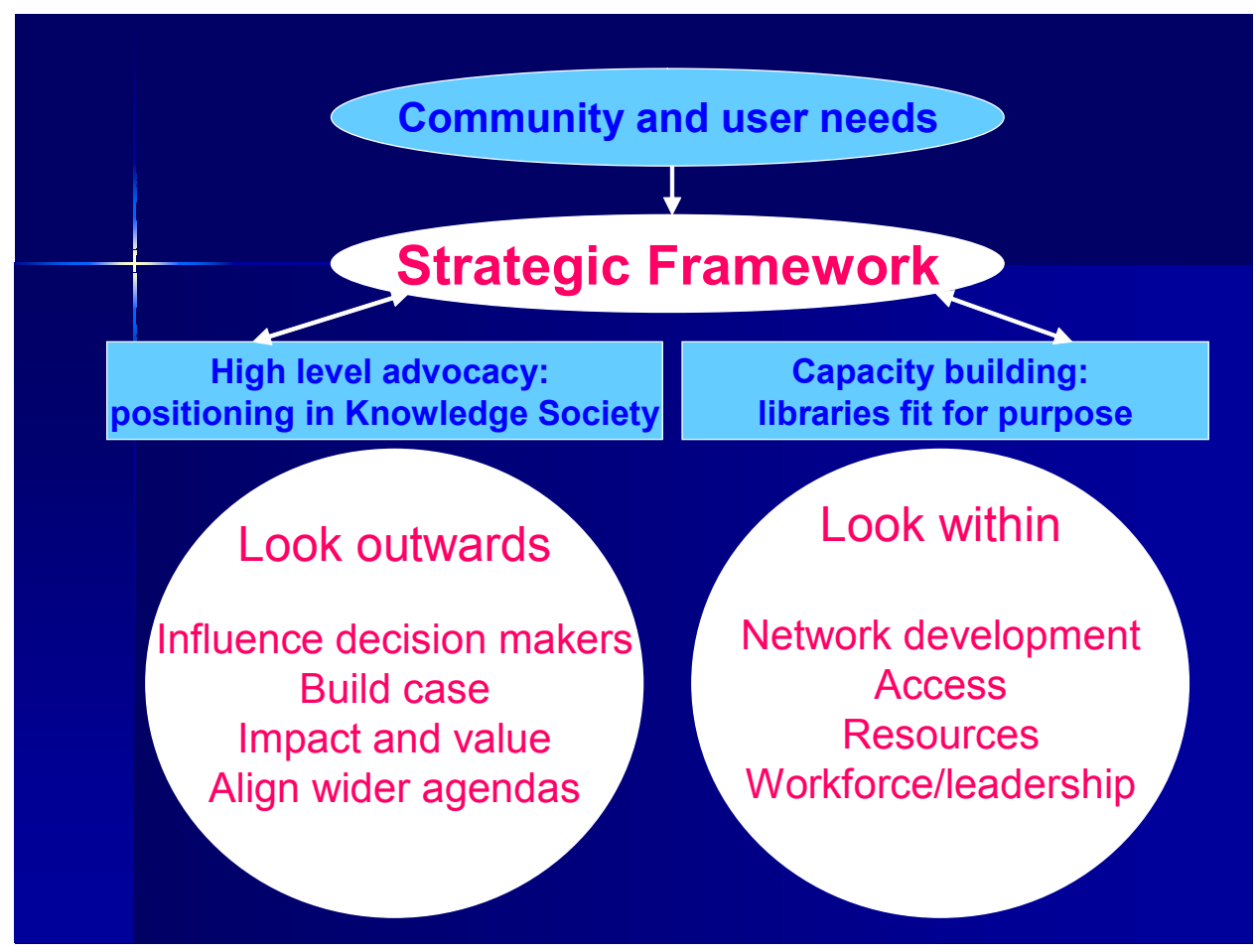

Figure 1: The Routes to Knowledge programme 
Community, organisational and user needs will drive forward work on the strategic framework for library and information services and the focus will be on advocacy on the one hand and, on the other, on activity to improve capacity to deliver.

\section{High level advocacy}

Work in 2004/5 will focus on establishing clarity over the key messages about library and information services and how they can most effectively be positioned to influence policy makers and decision makers, in particular at a national level. It is anticipated that the actual putting over of those messages will take place in the subsequent year as part of the run-up to the next government spending round. Advocacy will focus on working with government and major national agencies to understand better their agendas and show how library and information services can help deliver them, to demonstrate the substantial impact they have and to make the case for what they can potentially deliver when given the opportunity.

The case for library and information services is based on the conviction that they can raise their game and play a major role in delivering the Knowledge Society agenda. This is based on the following principles:

- Access to information has become a key factor in the way society functions

- Knowledge is the core business of libraries and information services

- Their services reach into all communities and they are in touch with their communities' needs and can help others reach them

- Libraries understand the "route map" for access to knowledge and enrich the lives of everyone in the community.

\section{Capacity building}

There will be focused work with a small number of specific types of library to identify how their impact and effectiveness can be improved through working together effectively, building stronger library networks and effective advocacy at institutional, regional and national level. This work will test what can be achieved. Wherever appropriate, issues will be addressed through existing programmes or activities. For example, the MLA workforce strategy will be used to plan how workforce and leadership issues may best be tackled across libraries as well as museums and archives. Improved co-ordination in this way will be cost-effective and will also maximise opportunities available to library and information services.

\section{How Routes will be delivered}

Routes is also about a process of continuing and developing the engagement with professional bodies begun by WILIP. These partnerships are crucial to creating new capacity and focus for improvement. The close working of the BL, CILIP and MLA will embrace more actively a wider constituency of professional bodies. A new Steering Group will be established by April 2004. It will represent major professional stakeholders in library and information services to advise the programme and help ensure effective communication with all library and information services.

Over the year from April 2004 to March 2005, Routes will test the validity of the view that library and information services can do much more if they work together effectively. The programme will focus on establishing how that potential can be unlocked, initially concentrating on making the best use of existing resources.

An Action Plan will be produced in April 2005, developed in partnership with leaders across the library and information world, and will be delivered from 2005/6. There is, of course, a large amount of excellent and important work already happening and that will be drawn on to shape the Action Plan. 


\section{Research and Routes}

In saying above that "there is .... large amount of excellent and important work already happening and that will be drawn on", research is meant as well as other types of initiative. Routes will also furnish further ideas for research.

As the work of the Steering Group progresses, investigations to be carried out (either in 2004/5 or beyond) will be identified. It is not possible to be definitive at this stage, therefore, about what topics will be further explored, but it is reasonable to assume that the areas of interest indicated in Figure 1 will all receive attention. In addition, other generic topics - for example, knowledge management and information literacy - emerged from the WILIP consultation as being of crucial importance and will be addressed.

Starting at the top of Figure 1 with users and community and organisational needs, there is much relevant research, both quantitative and qualitative - but how effectively are librarians using it to develop services?

The creation of a framework that links existing strategies and provides guidelines for the creation of new ones might well require research - for example, into current gaps and how best to fill them. Its existence could facilitate a more coordinated approach to research - for example, a range of impact measures could be developed that reflected needs of policy-makers across a number of types of library and information services.

The whole issue of influencing decision-makers and making the case to do so has been the subject of research in a range of disciplines. But do we have the necessary evidence of impact and value? MLA (then Resource) commissioned a review of the evidence of the impact of libraries, museums and archives currently available in a range of policy areas (Wavell et al, 2002). The conclusions of the study were disappointing: "While there is an abundance of anecdotal evidence and descriptions of best practice in the sector, extensive hard evidence of impact, gathered systematically, is often lacking." The solution may not be more research - or at least not research carried out without an understanding of how the results might best be used to influence policy-makers. Ian Johnson and others have written in a recent article: "It seems essential to provide future researchers and practitioners with a clearer understanding of policy-making, to appreciate, for example, how the policy-making process is politicised." (Johnson et al, 2004).

Again, we can expect that "thematic" work over 2004/5 will build on existing research relating to network development, access, resources, workforce/leadership and identify the need for further work in 2005/6 and beyond.

\section{Conclusion}

There is a very large task ahead in making sure the Knowledge Society draws full benefit from the accumulated skills and many years of acquired wisdom of the library and information profession. The way to do that is through making a powerful case for development and investment (and that must be done by gathering, marshalling and presenting the evidence) and ensuring that library and information services are "fit for new purpose" by working together more effectively, building stronger networks and tackling issues such as funding and workforce/leadership. The research community can and should make a crucial contribution to this process. 


\section{References}

Ede, S. (2003) Full Report of the WILIP Consultation Exercise. URL:

http://www.mla.gov.uk/documents/wilip_rep.pdf [1 March 2004]

Howley, S. and Ede, S. (2003) WILIP make a difference? Practitioner perspectives of the challenges facing libraries and information services, Library and Information Research 27 (85) Spring 2003, 5-10.

Howley, S. and Stevens, A. (2003) WILIP: Summary Report and next Steps. URL:

http://www.mla.gov.uk/documents/wilip_sum.pdf [1 March 2004]

Johnson, I., Williams, D., Wavell, C. and Baxter, G. (2004) Impact evaluation, professional practice, and policy making, New Library World 105 (1196/7), 33-46

Wavell, C., Baxter, G., Johnson, I. and Williams, D. (2002) Impact evaluation of museums, archives and libraries: available evidence project, London, Resource: The Council for Museums, Archives and Libraries, ISBN 1901085716. URL: http://www.mla.gov.uk/documents/id16rep.doc [1 March 2004]

\section{WORD COUNT: 2,514}

